\title{
Gene duplication and an accelerated evolutionary rate in 115 globulin genes are associated with higher protein synthesis in dicots as compared to monocots
}

\author{
Chun $\mathrm{Li}^{1,2+}$, Meng $\mathrm{Li}^{1 \dagger}, \operatorname{Jim~M}$ Dunwell ${ }^{3}$ and Yuan-Ming Zhang ${ }^{1 *}$
}

\begin{abstract}
Background: Seed storage proteins are a major source of dietary protein, and the content of such proteins determines both the quantity and quality of crop yield. Significantly, examination of the protein content in the seeds of crop plants shows a distinct difference between monocots and dicots. Thus, it is expected that there are different evolutionary patterns in the genes underlying protein synthesis in the seeds of these two groups of plants.
\end{abstract}

Results: Gene duplication, evolutionary rate and positive selection of a major gene family of seed storage proteins (the $11 \mathrm{~S}$ globulin genes), were compared in dicots and monocots. The results, obtained from five species in each group, show more gene duplications, a higher evolutionary rate and positive selections of this gene family in dicots, which are rich in 115 globulins, but not in the monocots.

Conclusion: Our findings provide evidence to support the suggestion that gene duplication and an accelerated evolutionary rate may be associated with higher protein synthesis in dicots as compared to monocots.

Keywords: $11 \mathrm{~S}$ globulin, dicot, evolutionary rate, gene duplication, legumins, monocot, positive selection

\section{Background}

The plant seed is not only an organ of propagation and dispersal but also the major plant tissue harvested and used either directly as part of the human diet or as feed for animals. At the present time there is concern over long term food security and the impact of the move towards meat-based diets that will lead to a significant increase in the demand for plant protein for animal feed [1]. The amount of protein present in plant seeds varies from $\sim 10 \%$ of the dry weight in most monocot (e.g. O. sativa, S. bicolor, S. italica, Z. mays and B. distachyon) to more than $30 \%$ in most dicots (e.g. G. max, R. communis, C. sativus and A. thaliana), and forms a major source of dietary protein [2-7]. To determine whether

\footnotetext{
* Correspondence: soyzhang@njau.edu.cn

† Contributed equally

${ }^{1}$ State Key Laboratory of Crop Genetics and Germplasm Enhancement, College of Agriculture, Nanjing Agricultural University, Nanjing 210095, P R China

Full list of author information is available at the end of the article
}

differences in evolutionary patterns may explain the phenotypic differences observed, a comparative investigation of evolutionary divergence in genes underlying protein synthesis in these two groups of plants is thus warranted.

Seed storage proteins can be classified into four groups: albumins, globulins, prolamins and glutelins [8]. Albumins and globulins comprise the storage proteins of dicots, whereas prolamins and glutelins are the major proteins in monocots $[4,9,10]$. $2 \mathrm{~S}$ albumins, a major class of dicot seed storage proteins, have been most widely studied in the Cruciferae, notably B. napus and A. thaliana $[9,10]$. Prolamins, the major endosperm storage proteins of all cereal grains, with the exceptions of oats and rice, can be classified into many subgroups, e.g. sulphur-rich (S-rich), sulphur-poor (S-poor) and high molecular weight (HMW) prolamins [4]. The globulins, the most widely distributed group of storage proteins, are part of the cupin superfamily [11] and are evolved from bacterial enzymes. The globulins are present not only in dicots but 
also in monocots [9] and can be divided into 7S vicilintype and $11 \mathrm{~S}$ legumin-type globulins according to their sedimentation coefficients. It should be noted that the genes encoding the 11S-type globulins in monocots are the same gene family, $11 \mathrm{~S}$ globulin family, as those in dicots; whereas the genes encoding the 7S-type globulins in monocots are not evolutionarily related to those in dicots [4]. Thus, we focus on the genes encoding the 11S-type globulins in this study.

Many efforts have been made to describe the gene families encoding seed storage proteins. For albumins, they are encoded by multi-gene families in many dicots (e.g., A. thaliana and B. napus); and evolutionary research into the gene families suggests that the albumin genes were duplicated prior to the Brassiceae-Sysimbrieae split, and gene duplication has played a role in their evolution $[12,13]$. For prolamins, they are the major seed storage proteins in most grass species (e.g., Z. mays and $S$. bicolor); and studies have suggested that the prolamin gene families have undergone many rounds of gene duplication $[14,15]$. For globulins, eight, four, eleven and fourteen gene have been identified and classified in G. max, A. thaliana, R. communis and O. sativa, respectively [16-24].

From the research described above, it can be concluded that the seed storage protein gene families have expanded in a lineage-specific manner through gene duplication. As a major process in the evolution, gene duplications can provide raw material for evolution by producing new copies. The human globin gene family is a representative example: several globin genes have arisen from a single ancestral precursor, thus making individual genes available to take on specialized roles, with some genes becoming active during embryonic and fetal development, and others becoming active in the adult organism [25]. Gene duplications may also affect phenotype by altering gene dosage: the amount of protein synthesized is often proportional to the number of gene copies present, so extra genes can lead to excess proteins. This applies to many kinds of genes, such as rRNAs, tRNA and histones $[26,27]$. A critical question thus can be asked: does gene duplication contribute to the higher levels of protein synthesis in dicots than in monocots? On the other hand, gene duplication usually brings variation in evolutionary rate [26], and such variation has been predicted to be associated with phenotypic differences. For example, Hunt et al. [28] investigated the evolution of genes associated with phenotypically plastic castes, sexes, and developmental stages of the fire ant Solenopsis invicta, and argued that an elevated rate is a precursor to the evolution of phenotypic differences. Thus, we are also interested in another question: does an accelerated evolutionary rate play a role in the evolution of storage protein content?
To shed light on the two questions above, we investigated the process of molecular evolution of the $11 \mathrm{~S}$ globulin gene family, which is widely distributed in dicot and monocot species, by comparing the differing evolutionary patterns in the two groups. Our analyses suggested that gene duplication and an accelerated evolutionary rate in $11 \mathrm{~S}$ globulin genes may be associated with higher protein synthesis in dicots than in monocots.

\section{Results}

\section{Sequences retrieval and phylogenetic analysis}

We collect the sequences of $11 \mathrm{~S}$ globulin genes through a COG method. This procedure is based a simple notion that, if any proteins from distant genomes are more similar to each other than to any other proteins from the same genomes, they are most likely to belong to an orthologous family. In such a family, there are two kinds of relationship between a pair of sequences, namely symmetrical and asymmetrical BeTs (the Best Hits). If the symmetrical and asymmetrical BeTs are linked respectively by solid and broken lines, the orthologous family would forms a network; and thus all other members in the network can be identified when one member was investigated [29]. The 11S globulin genes from the five dicots and the five monocots form a COG containing 56 sequences (Figure 1). Of these genes, four genes encoding $12 S$ globulins [20] come from A. thaliana; six genes, Gy1-Gy5 and Gy7 [16], come from G. max; twelve genes, all the functional glutelin genes, come from $O$. sativa [24]; eleven genes described in [7] come from R. communis; and six, seven, six, one, one and two genes come from C. sativus, P. trichocarpa, B. distachyon, Z. mays, S. bicolor and S. italica, respectively.

In order to analyze the phylogenetic relationship of the $11 \mathrm{~S}$ globulin genes from the above ten species, the NJ and Bayesian methods were used to reconstruct the phylogenetic tree. Similar results were achieved (data not shown), and the NJ tree is shown in Figure 2, in which there are three subfamily clades: dicot subfamily 1 , dicot subfamily 2 and monocot subfamily. The dicot subfamily 1 contains all the genes from A. thaliana and G. max, two genes from $C$. sativus, two genes from $P$. trichocarpa and RcLEG1 of $R$. communis; the dicot subfamily 2 contains the other genes from C. sativus, $P$. trichocarpa and $R$. communis; and the monocot subfamily contains all the genes from the five monocot species. In the three subfamilies, with the exception of rice, genes from the same species form monophyletic groups; and the phylogenetic relationship of the monophyletic groups is largely concordant with the species tree described by [30].

\section{Gene duplication in $11 \mathrm{~S}$ globulin gene family}

In the $11 \mathrm{~S}$ globulin gene family, there are four or more genes from $C$. sativus, $P$. trichocarpa, $R$. communis, 


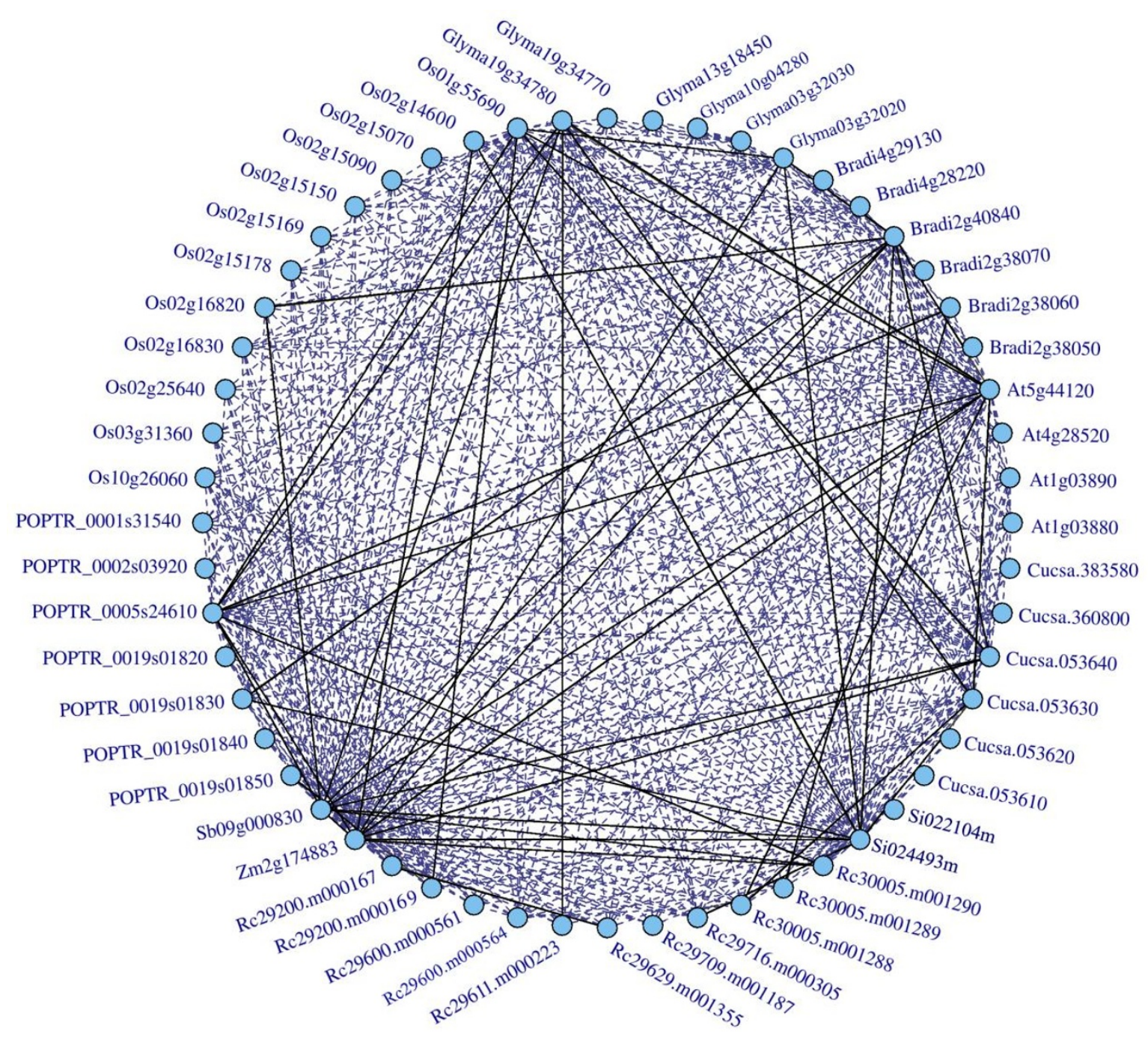

Figure 1 The COG of $11 \mathrm{~S}$ globulin gene family. Solid lines show symmetrical BeTs (the Best Hits) and broken lines show asymmetrical BeTs. Genes from the same species are adjacent. Gene ID is indicated and the prefix "Rc" denotes IDs from Ricinus communis. Among these IDs, At1g03880, At1g03890, At4g28520 and At5g44120 are known to encode CRB, CRU2, CRC and CRA1, respectively; Glyma03g32030,

Glyma03g32020, Glyma19g34780, Glyma10g04280, Glyma13g18450 and Glyma19g34770 to encode Gy1-5 and Gy7, respectively; Rc29600. m000561, Rc29600.m000564, Rc30005.m001289, Rc30005.m001290, Rc29611.m000223, Rc29200.m000169, Rc29629.m001355, Rc29709.m001187, Rc29716.m000305, Rc29200.m000167 and Rc30005.m001288 to encode RcLEG1-1 to RCLEG1-5 and RcLEG2-1 to RcLEG2-6, respectively; and Os01g55690, Os10g26060, Os03g31360, Os02g15169, Os02g15178, Os02g15150, Os02g16820, Os02g16830, Os02g14600, Os02g15070, Os02g25640 and Os02g15090 to encode GluA-1, GluA-2, GluA-3, GluB-1a, GluB-1b, GluB-2, GluB-5, GluB-4, GluB-7, GluB-6, GluC-1 and GluD, respectively.

A. thaliana, G. max, B. distachyon and O. sativa, suggesting that the $11 \mathrm{~S}$ globulin genes in these species have undergone two or more rounds of duplication. Among these duplications, tandem duplication is a major type, and occurred in all the species above, e.g. Rc30005. m001289-Rc30005.m001290 and At1g03880-At1g03890 and Os02g16820-Os02g16830. Furthermore, most of the $11 \mathrm{~S}$ globulin genes from the dicot species are located on the chromosome segments that share conserved synteny with each other [18], suggesting that segment duplication or whole genome duplication (WGD) is the major origin of duplicate genes.

\section{Evolutionary rate of $11 \mathrm{~S}$ globulin gene family}

To determine whether there were different evolutionary patterns across different subfamilies of the $11 \mathrm{~S}$ globulin genes in monocots and dicots, the $\omega$ values for these genes were calculated by a branch-specific model.

In the branch-specific model, three cases were considered in this study. One is a two-ratio model that 


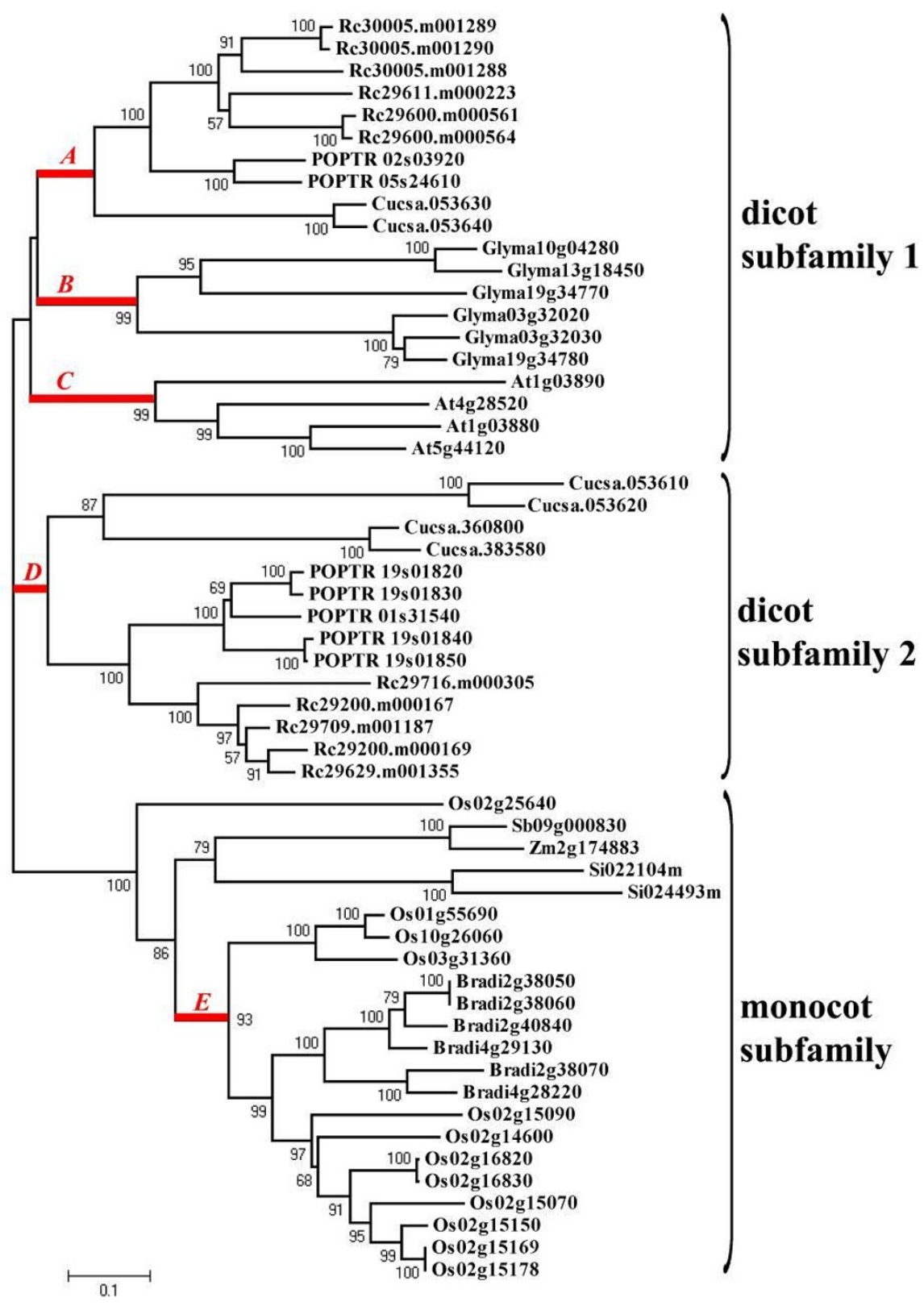

Figure 2 Phylogenetic relationships of sequences within the $11 \mathrm{~S}$ globulin gene family by neighbor joining (NJ) method with bootstrap support above $\mathbf{5 0} \%$ shown at the nodes. Letter $A-E$ indicates the branches used in analysis of evolutionary rate and positive selection.

suggests there are distinct monocot $\left(\omega_{0}\right)$ and dicot subfamilies $\left(\omega_{1}\right)$, one is a three-ratio model that suggests there is one monocot $\left(\omega_{0}\right)$ and two dicot subfamilies 1 $\left(\omega_{1}\right)$ and $2\left(\omega_{2}\right)$, and one is a six-ratio model that suggests there are subclades under the branches $A-E\left(\omega_{1} \sim\right.$ $\left.\omega_{5}\right)$ and the other $\left(\omega_{0}\right)$. All the above models were favored over the one-ratio model by the likelihood ratio test $(\mathrm{P}<0.05$, Table 1$)$ and in the two-, three- and sixratio models, the $\omega$ estimate for the dicot subfamily is considerably higher than that for the monocot subfamily. These results suggest that the dicot $11 \mathrm{~S}$ globulin genes are under reduced evolutionary constraints, and thus evolve at a higher evolutionary rate. We should point out that in the six-ratio model, the genes from S. italica, Z. mays and S. bicolor were not taken into account, because they may have a different evolutionary pattern due to the fact that $11 \mathrm{~S}$ globulins are minor components $[4,31]$ and there are only one or two $11 \mathrm{~S}$ 
Table 1 Evolutionary rate analysis of $11 \mathrm{~S}$ globulin family using branch-specific model of PAML

\begin{tabular}{|c|c|c|c|c|}
\hline Model & $\omega$ setting & $-\ln \mathrm{L}$ & Estimated parameters & Likelihood ratio test \\
\hline One-ratio & entire tree: $\omega_{0}$ & 38214.64 & $\omega_{0}=0.234$ & \\
\hline \multirow[t]{2}{*}{ Two-ratio } & monocot subfamily: $\omega_{0}$ & 38210.14 & $\omega_{0}=0.212$ & two ratio vs. one ratio: $P<0.01$ \\
\hline & dicot subfamily $1 \& 2: \omega_{1}$ & & $\omega_{1}=0.249$ & \\
\hline \multirow[t]{3}{*}{ Three-ratio } & monocot subfamily: $\omega_{0}$ & 38209.98 & $\omega_{0}=0.212$ & three ratio vs. one ratio: $P<0.01$ \\
\hline & dicot subfamily $1: \omega_{1}$ & & $\omega_{1}=0.252$ & three ratio vs. two ratio: $P>0.05$ \\
\hline & dicot subfamily $2: \omega_{2}$ & & $\omega_{2}=0.243$ & \\
\hline \multirow[t]{6}{*}{ Six-ratio } & branch $A: \omega_{1}$ & 38182.58 & $\omega_{1}=0.225$ & six ratio vs. one ratio: $P<0.01$ \\
\hline & branch $B: \omega_{2}$ & & $\omega_{2}=0.373$ & six ratio vs. two ratio: $P<0.01$ \\
\hline & branch C: $\omega_{3}$ & & $\omega_{3}=0.198$ & six ratio vs. three ratio: $P<0.01$ \\
\hline & branch $D: \omega_{4}$ & & $\omega_{4}=0.242$ & \\
\hline & branch $E: \omega_{5}$ & & $\omega_{5}=0.187$ & \\
\hline & other branches: $\omega_{0}$ & & $\omega_{0}=0.283$ & \\
\hline
\end{tabular}

globulin gene copies in these species; and that branches $A-E$ were chosen because five branches can be grouped for the phylogenetic tree.

\section{Positive selection in the $11 \mathrm{~S}$ globulin genes}

To test for positive selection in the $11 \mathrm{~S}$ globulin gene family, branches $A, B, C, D$ and $E$ were independently defined as the foreground branch in the branch-site model (Figure 2). When branches $A, B, C$ or $D$ were defined as the foreground branch, the null hypothesis is rejected ( $P$ $<0.01)$; and the estimated parameters of the alternative hypotheses indicate that about $5 \%-11 \%$ sites on these branches were under positive selection with a $\omega$ value $\left(\omega_{2}\right)$ larger than one. When branch $E$ was brought to the foreground, the null hypothesis cannot be rejected, and thus no significant positive selection was detected (Table 2). This result suggests that positive selection mainly occurred in the $11 \mathrm{~S}$ globulin genes in dicots.

\section{Discussion and Conclusions}

Gene duplication may be associated with the higher $11 \mathrm{~S}$ globulin content in dicots

In our duplication analyses, we found four or more $11 \mathrm{~S}$ globulin genes in each of the five dicot species analyzed.
It appears that higher number of duplicates is a feature of the dicot $11 \mathrm{~S}$ globulin genes, rather than being randomly produced by the hitchhiking effect of genome duplication, because:

i) The copy number of the dicot $11 \mathrm{~S}$ globulin gene is higher than the average copy number of the genome; for example, in the genome of $A$. thaliana, $80 \%$ of genes recovered to single copy through gene loss in a short period after the duplications, resulting an average of 2.3 copies per family [32], which is lower than the 4 duplicates in the $11 \mathrm{~S}$ globulin gene family; in the genome of G. $\max , 74.1 \%$ and $56.6 \%$ genes were lost following the early and the recent WGD, respectively, resulting an average of about 3 copies per family $[33,34]$, which is lower than the 6 duplicates in the globulin gene family;

ii) In each of the five dicots, there are $11 \mathrm{~S}$ globulin genes that arose from tandem duplications; and

iii) The genomes of S. italica, Z. mays and S. bicolor are thought to have undergone several rounds of duplications $[35,36]$, but they contain only one or two $11 \mathrm{~S}$ globulin genes, suggesting that gene losses are common in the family, and thus implying that

Table 2 Summary statistics for detecting selection using branch-site models of PAML

\begin{tabular}{|c|c|c|c|c|}
\hline \multirow[t]{2}{*}{ Foreground branch } & \multicolumn{2}{|c|}{ Null hypothesis } & \multicolumn{2}{|c|}{ Alternative hypothesis } \\
\hline & $-\ln L$ & Estimated parameters & $-\ln L$ & Estimated parameters \\
\hline \multirow[t]{2}{*}{ Branch $A$} & 46859.30 & $p_{0}=0.66, p_{1}=0.28\left(p_{2}+p_{3}=0.06\right)$ & $46851.6^{* *}$ & $p_{0}=0.69, p_{1}=0.27\left(p_{2}+p_{3}=0.04\right)$ \\
\hline & & $\omega_{0}=0.23, \omega_{1}=\omega_{2}=1$ & & $\omega_{0}=0.23, \omega_{1}=1.00, \omega_{2}=999$ \\
\hline \multirow[t]{2}{*}{ Branch $B$} & 46854.00 & $p_{0}=0.53, p_{1}=0.22\left(p_{2}+p_{3}=0.25\right)$ & $46837.66^{* *}$ & $p_{0}=0.63, p_{1}=0.26\left(p_{2}+p_{3}=0.11\right)$ \\
\hline & & $\omega_{0}=0.23, \omega_{1}=\omega_{2}=1$ & & $\omega_{0}=0.23, \omega_{1}=1.00, \omega_{2}=56.08$ \\
\hline \multirow[t]{2}{*}{ Branch $C$} & 46852.38 & $p_{0}=0.53, p_{1}=0.21\left(p_{2}+p_{3}=0.36\right)$ & $46831.76^{* *}$ & $p_{0}=0.64, p_{1}=0.26\left(p_{2}+p_{3}=0.10\right)$ \\
\hline & & $\omega_{0}=0.23, \omega_{1}=\omega_{2}=1$ & & $\omega_{0}=0.23, \omega_{1}=1.00, \omega_{2}=526.55$ \\
\hline \multirow[t]{2}{*}{ Branch $D$} & 46859.11 & $p_{0}=0.61, p_{1}=0.26\left(p_{2}+p_{3}=0.13\right)$ & $46842.30^{* *}$ & $p_{0}=0.68, p_{1}=0.27\left(p_{2}+p_{3}=0.05\right)$ \\
\hline & & $\omega_{0}=0.23, \omega_{1}=\omega_{2}=1$ & & $\omega_{0}=0.23, \omega_{1}=1.00, \omega_{2}=999$ \\
\hline \multirow[t]{2}{*}{ Branch $E$} & 46859.33 & $p_{0}=0.70, p_{1}=0.30\left(p_{2}+p_{3}<0.01\right)$ & 46859.33 & $p_{0}=0.70, p_{1}=0.30\left(p_{2}+p_{3}<0.01\right)$ \\
\hline & & $\omega_{0}=0.23, \omega_{1}=\omega_{2}=1$ & & $\omega_{0}=0.23, \omega_{1}=\omega_{2}=1$ \\
\hline
\end{tabular}

Note: ${ }^{* *} P<0.01$, calculated from LRT. 
the duplicates of the 11S globulin genes are preferentially retained in the dicot species.

We hypothesize that the higher number of duplicates may be associated with higher $11 \mathrm{~S}$ globulin content in dicots. The reasons are as follows.

First, the seed $11 \mathrm{~S}$ globulin content in the species with a higher copy number of $11 \mathrm{~S}$ globulin genes is greater than that in those with a lower copy number (Table 3). In the dicot species A. thaliana, R. communis, G. max and $C$. sativus, the copy number of $11 \mathrm{~S}$ globulin genes is four or more, and the $11 \mathrm{~S}$ globulins are predominant among the seed storage proteins $[2,5,20,37-41]$. In the monocot species $S$. italica, Z. mays and S. bicolor, the copy number of $11 \mathrm{~S}$ globulin genes is one or two, and $11 \mathrm{~S}$ globulins are minor $[4,31]$. However, there are two exceptions, $O$. sativa and $B$. distachyon (monocots). In these two species, the copy number of $11 \mathrm{~S}$ globulin genes is six or more and the $11 \mathrm{~S}$ globulins are predominant among the seed storage proteins [6,42-44], although the overall protein content is low.

Second, the presence of duplicate genes leads to the production of an extra amount of protein, because extra mRNA can be produced [26]. There is some evidence for this viewpoint: i) the absence of, or preferential expression of, the 11S globulin genes in G. max leads to glycinin deficiency or greater accumulation, respectively $[45,46]$; ii) of the glycinin gene groups I (Gy1-Gy3), IIa (Gy4) and IIb (Gy5) in G. max, a mutation with the absence of one or two groups of genes leads to a decrease in glycinin content [47]; and simultaneous mutation of all the genes leads to the lack of all the glycinin polypeptides [48]. Third, enlarging the $2 \mathrm{~S}$ albumin gene family of $A$. thaliana by introducing an extra member leads to an increase in transcript production [49].

Finally, in the investigation of ancestral whole genome duplication in seed plants and angiosperms, Jiao et al. [50] proposed that there were two WGDs in ancestral lineages shortly before the diversification of extant seed plants and extant angiosperms respectively, and argued that these ancestral WGDs i) resulted in the diversification of regulatory genes important to seed and flower development; ii) were involved in major innovations that ultimately contributed to the rise and eventual dominance of seed plants and angiosperms; and iii) enabled flowering plants to enjoy a distinct evolutionary advantage that allowed them to survive harsh climatic changes and even mass extinctions. The seed storage proteins provide essential nutrition for seed germination and development, and thus are vital for species survival and adaptation. Therefore, the genes governing the seed storage proteins are expected to have a higher number of duplications, leading to improved phenotypic robustness and an evolutionary advantage.

\section{Higher evolutionary rate may be associated with the higher $11 \mathrm{~S}$ globulin content in dicots}

In the evolutionary rate analyses, a consistent conclusion, that the dicot $11 \mathrm{~S}$ globulin genes evolve more rapidly, was achieved from the three branch-specific models, i.e. two-, three- and six-ratio models (Table 1). We hypothesize that accelerated evolutionary rate may also be associated with the higher $11 \mathrm{~S}$ globulin content in dicots. The reasons are as follows.

Positive selection leads to an accelerated evolutionary rate of the $11 \mathrm{~S}$ globulin genes in dicots, and may also lead to a higher ability of dicots to produce $11 \mathrm{~S}$ globulins. Positive selection is a major factor affecting the evolutionary rate of a gene [51]. To investigate evidence for positive selection in the $11 \mathrm{~S}$ globulin genes, we analyzed five branches, i.e. branches $A-E$ (Figure 2), which represent the major origin events in the evolution of the $11 \mathrm{~S}$ globulin gene families, e.g. branch $B$ represents the origin of G. $\max 11 \mathrm{~S}$ globulin gene family. Of these branches, branches $A-D$, being the dicot 11S globulin genes, were proved to have undergone positive selection, whereas branch $E$, being the monocot $11 \mathrm{~S}$ globulin genes, did not. This result provides evidence that

Table 3 The content of seed $11 \mathrm{~S}$ globulins and the copy number of their genes

\begin{tabular}{|c|c|c|c|c|}
\hline Group & Species & Seed storage protein ${ }^{1}$ & $11 \mathrm{~S}$ globulins ${ }^{2}$ & No. of genes \\
\hline \multirow[t]{5}{*}{ dicot } & Arabidopsis thaliana & $30-40 \%$ & major component & 4 \\
\hline & Glycine max & $\sim 40 \%$ & $\sim 40 \%$ & 6 \\
\hline & Cucumis sativus & $\sim 35 \%$ & major component & 6 \\
\hline & Populus trichocarpa & major component & unknown & 7 \\
\hline & Ricinus communis & $\sim 40 \%$ & $\sim 75 \%$ & 11 \\
\hline \multirow[t]{5}{*}{ monocot } & Brachypodium distachyon & $<10 \%$ & $\sim 60 \%$ & 6 \\
\hline & Oryza sativa & $<10 \%$ & $\sim 70 \%$ & 12 \\
\hline & Setaria italica & $\sim 10 \%$ & minor component & 2 \\
\hline & Zea mays & $\sim 7 \%$ & minor component & 1 \\
\hline & Sorghum bicolor & $<10 \%$ & minor component & 1 \\
\hline
\end{tabular}

Note: ${ }^{1}$ percentage to the seed dry weight; ${ }^{2}$ percentage to the seed storage protein. The references are listed in the main text. 
positive selection may lead to a higher ability of dicots to produce $11 \mathrm{~S}$ globulins.

To shed more light on the role of gene duplication and accelerated rates of evolution in producing the observed patterns of divergence in protein synthesis between dicots and monocots, future studies investigating other types of seed storage proteins and a broader range of plant species will be needed.

\section{Methods}

\section{Sequences Retrieval and Comparisons}

Sequences retrieval and comparisons were performed using the method described by Tatusov et al. [29] with a slight modification. Briefly, our method included the following steps:

1) Amino acid sequences of proteins were downloaded from JGI (http://www.phytozome.net/), the maize sequence from http://www.maizesequence.org, and used to construct a local BLAST database using BLAST 2.2.24. The species are listed in Table 4.

2) An all-against-all protein sequence comparison was carried out.

3) In all the comparisons produced in the step 2, the ones with G. $\max G y 1$ [16] as a query were identified, and the obvious paralogs were collapsed.

4) All interspecies Best Hits (BeTs) of Gy1 and their paralogs were detected.

5) Steps 3) and 4) were repeated, with the resulting sequences as secondary BLASTp queries until no new sequence was found.

6) The protocol of Tatusov et al. [29] was applied to all the sequences from the analysis above and used to form a Clusters of Orthologous Groups (COG).

7) A case-by-case analysis of the COG was conducted. This analysis served to eliminate false-positives and to ensure all homologs were included.

This approach was based on the consistency between genome-specific best hits, rather than the absolute level of similarity; it therefore allows the detection of orthologs among both slowly and quickly evolving genes.

\section{Phylogenetic Analyses}

The cDNA sequences were aligned using the codon model of program PRANK (100701 version) using the default options [52], and were then translated into amino acid sequences. Phylogenetic tree reconstruction was carried out using both Neighbor-Joining (NJ) and Bayesian approaches based on the aligned amino acid sequences. In the NJ method, the phylogenetic analyses were conducted using the MEGA 5 program [53]. The parameter setups were as follows: model, Jones-Taylor-Thornton (JTT) [54]; bootstrap, 1000 replicates; and gap/missing data, pairwisedeletion.

In the Bayesian method, the analyses were conducted using MrBayes v3.1 [55]. The parameter setups were as follows: JTT substitution model, four chains, one million generations, two runs, sampling every 100 generations and discarding a burn-in of 250,000 generations.

\section{Estimation of $d_{N} / d_{s}$ Ratios}

The coding sequences were aligned using the codon model of PRANK software (100701 version) using the default options [52], and alignment gaps were deleted manually.

On the basis of the aligned coding sequences, the pairwise ratio of non-synonymous substitutions per non-synonymous site $\left(d_{\mathrm{N}}\right)$ to the synonymous substitutions per synonymous site $\left(d_{\mathrm{S}}\right)$ ( $\omega$ value) of homologous genes was calculated by the maximum likelihood method in Codeml from the PAML package v4.4 [56]. Saturation effects were avoided by discarding the gene pairs for which $d_{\mathrm{S}}>2$ [57].

The branch-specific model, which allows the $\omega$ ratio to vary among the branches in the phylogeny, was used to test whether there are different $\omega$ values on particular lineages [58]. If the $\omega$ ratio among all the branches is a constant, the model can be changed into the one-ratio model. Thus the likelihood ratio test (LRT) was used to test whether the data fit the branch-specific model significantly better than the one-ratio model [58].

Table 4 Source of the $11 \mathrm{~S}$ globulin genes used in this study

\begin{tabular}{|c|c|c|c|c|c|}
\hline Group & Common name & Species name & Version & No of genes & Reference \\
\hline \multirow[t]{5}{*}{ dicot } & thale cress & Arabidopsis thaliana & TAIR 9 & 33,410 & {$[62]$} \\
\hline & soybean & Glycine max & 1.0 & 75,778 & [34] \\
\hline & cucumber & Cucumis sativus & 122 & 32,509 & {$[63]$} \\
\hline & black cottonwood & Populus trichocarpa & 2.0 & 45,778 & {$[64]$} \\
\hline & castor bean & Ricinus communis & 0.1 & 31,221 & {$[65]$} \\
\hline \multirow[t]{5}{*}{ monocot } & purple false brome & Brachypodium distachyon & 1.0 & 32,255 & {$[66]$} \\
\hline & rice & Oryza sativa & MSU 6.0 & 67,393 & {$[67]$} \\
\hline & foxtail millet & Setaria italica & 2.1 & 38,038 & \\
\hline & maize & Zea mays & $5 a$ & 53,764 & {$[68]$} \\
\hline & sorghum & Sorghum bicolor & 1.0 & 36,338 & [69] \\
\hline
\end{tabular}




\section{Detection of Positive Selection}

The aligned codon sequences were used to test positive selection using the branch-site model implemented in the program Codeml of PAML 4.4 [56]. This model allows $\omega$ to vary both among sites in the sequences and across branches on the tree and its purpose is to detect positive selection affecting a few sites along particular lineages (called foreground branches). The model assumes that there are four site classes in the sequence. The first class of sites is highly conserved in all lineages with a small $\omega$ ratio, $\omega_{0}$. The second class includes neutral or weakly constrained sites for which $\omega=\omega_{1}$, where $\omega_{1}$ is near or smaller than 1 . In the third and fourth classes, the background lineages show $\omega_{0}$ or $\omega_{1}$, but foreground branches have $\omega_{2}$, which may be greater than 1 . In the LRT, the null hypothesis fixes $\omega_{2}=1$ (neutral selection) and the alternative hypothesis constrains $\omega_{2} \geq 1$ (positive selection) [59,60]. In the existence of positive selection, the posterior probabilities for the sites with positive selection were calculated by the Bayes empirical Bayes method (BEB) [61].

\section{Abbreviations}

BEB: the Bayes empirical Bayes; BeTs: Best Hits; COG: Clusters of Orthologous Groups; HMW: high molecular weight; JTT: Jones-Taylor-Thornton; LRT: likelihood ratio test; NJ: Neighbor Joining; WGD: whole genome duplication

\section{Acknowledgements}

We are grateful to Dr Hugo Zheng at McGill University for help with improvements to the English text. This work was supported by the National Basic Research Program of China (2011CB109300), the National Natural Science Foundation of China (30971848), the Fundamental Research Funds for the Central Universities (KYT201002, KJ2011003), the Specialized Research Fund for the Doctoral Program of Higher Education (20100097110035), and a Project Funded by the Priority Academic Program Development of Jiangsu Higher Education Institutions.

\section{Author details}

'State Key Laboratory of Crop Genetics and Germplasm Enhancement, College of Agriculture, Nanjing Agricultural University, Nanjing 210095, P R China. ${ }^{2}$ Henan Sesame Research Center, Henan Academy of Agricultural Sciences, Zhengzhou 450002, P R China. ${ }^{3}$ School of Biological Sciences, University of Reading, Whiteknights, Reading RG6 6AS, UK.

\section{Authors' contributions}

YMZ designed the study, coordinated and supervised the analysis. $C L$ and $M L$ performed the analysis and drafted the paper. YMZ and JMD revised the manuscript. All authors read and approved the final manuscript.

Received: 15 August 2011 Accepted: 31 January 2012 Published: 31 January 2012

\section{References}

1. OECD/FAO: OECD-FAO Agricultural Outlook 2011-2020, OECD Publishing and FOA. 2011 [http://dx.doi.org/10.1787/agr_outlook-2011-en].

2. Jacks TJ, Hensarling TP, Yatsu LY: Cucurbit seeds: I. Characterizations and uses of oils and proteins. A Review. Econ Bot 1972, 26:135-141.

3. Derbyshire E, Wright DJ, Boulter D: Legumin and vicilin, storage proteins of legume seeds. Phytochemistry 1976, 15:3-24.

4. Shewry PR, Halford NG: Cereal seed storage proteins: structures, properties and role in grain utilization. J Exp Bot 2002, 53:947-958.
5. Baud S, Dubreucq B, Miquel M, Rochat C, Lepiniec L: Storage reserve accumulation in Arabidopsis: metabolic and developmental control of seed filling. The Arabidopsis Book 2008, 6:e0113.

6. Larré C, Penninck S, Bouchet B, Lollier V, Tranquet O, Denery-Papini S, Guillon F, Rogniaux H: Brachypodium distachyon grain: identification and subcellular localization of storage proteins. J Exp Bot 2010, 61:1771-1783.

7. Chileh T, Esteban-García B, Alonso DL, García-Maroto F: Characterization of the $11 \mathrm{~S}$ globulin gene family in the castor plant Ricinus communis L. J Agric Food Chem 2010, 58:272-281.

8. Osborne TB: The Vegetable Proteins. Monographs in Biochemistry. London: Longmans, Green and Co; 1924, xiii+154.

9. Shewry PR, Napier JA, Tatham AS: Seed storage proteins: structures and biosynthesis. Plant Cell 1995, 7:945-956.

10. Mandal S, Mandal RK: Seed storage proteins and approaches for improvement of their nutritional quality by genetic engineering. Curr Sci 2000, 79:576-589.

11. Dunwell JM, Purvis A, Khuri S: Cupins: The most functionally diverse protein superfamily? Phytochemistry 2004, 65:7-17.

12. Krebbers E, Herdies L, De Clercq A, Seurinck J, Leemans J, Van Damme J, Segura M, Gheysen G, Van Montagu M, Vandekerckhove J: Determination of the processing sites of an Arabidopsis 25 albumin and characterization of the complete gene family. Plant Physiol 1988, 87:859-866.

13. Boutilier K, Hattori J, Baum BR, Miki BL: Evolution of $2 \mathrm{~S}$ albumin seed storage protein genes in the Brassicaceae. Biochem Syst Ecol 1999, 27:223-234.

14. $\mathrm{Xu} \mathrm{JH}$, Messing J: Organization of the prolamin gene family provides insight into the evolution of the maize genome and gene duplications in grass species. Proc Natl Acad Sci USA 2008, 105:14330-14335.

15. $\mathrm{Xu} \mathrm{JH}$, Bennetzen $J \mathrm{~L}$, Messing J: Dynamic gene copy number variation in collinear regions of grass genomes. $\mathrm{Mol}$ Biol Evol

16. Nielsen NC, Dickinson CD, Cho TJ, Thanh VH, Scallon BJ, Fischer RL, Sims TL, Drews GN, Goldberg RB: Characterization of the glycinin gene family in soybean. Plant Cell 1989, 1:313-328.

17. Beilinson V, Chen Z, Shoemaker RC, Fischer RL, Goldberg RB, Nielsen NC: Genomic organization of glycinin genes in soybean. Theor App/ Genet 2002, 104:1132-1140

18. Li C, Zhang YM: Molecular evolution of glycinin and $\beta$-conglycinin gene families in soybean (Glycine max L. Merr.). Heredity 2011, 106:633-641.

19. Pang PP, Pruitt RE, Meyerowitz EM: Molecular cloning, genome organization, expression and evolution of $12 \mathrm{~S}$ seed storage protein genes of Arabidopsis thaliana. Plant Mol Biol 1988, 11:805-820.

20. Fujiwara T, Nambara E, Yamagishi K, Goto DB, Naito S: Storage proteins. The Arabidopsis Book 2002, 1:e0020.

21. Higuchi W, Fukazawa C: A rice glutelin and a soybean glycinin have evolved from a common ancestral gene. Gene 1987, 55:245-253.

22. Takaiwa F, Kikuchi S, Oono K: A rice glutelin gene family: a major type of glutelin mRNAs can be divided into 2 classes. Mol Gen Genet 1987, 208:15-22.

23. Takaiwa F, Oono K, Wing D, Kato A: Sequence of three members and expression of a new major subfamily of glutelin genes from rice. Plant Mol Biol 1991, 17:875-885.

24. Kawakatsu T, Yamamoto MP, Hirose S, Yano M, Takaiwa F: Characterization of a new rice glutelin gene GluD-1 expressed in the starchy endosperm. $J$ Exp Bot 2008, 59:4233-4245.

25. Hardison R, Slightom JL, Gumucio DL, Goodman M, Stojanovic N, Miller W: Locus control regions of mammalian beta-globin gene clusters: combining phylogenetic analyses and experimental results to gain functional insights. Gene 1997, 205:73-94.

26. Zhang JZ: Evolution by gene duplication: an update. Trends Ecol Evol 2003, 18:292-298.

27. Clancy S, Shaw K: DNA deletion and duplication and the associated genetic disorders. Nature Education 2008, 1 -(1)[http://www.nature.com scitable/topicpage/DNA-Deletion-and-Duplication-and-the-Associated-331].

28. Hunt BG, Ometto L, Wurm Y, Shoemaker D, Yi SV, Keller L, Goodisman MA: Relaxed selection is a precursor to the evolution of phenotypic plasticity. Proc Natl Acad Sci USA 2011, 108:15936-15941.

29. Tatusov RL, Galperin MY, Natale DA, Koonin EV: The COG database: a tool for genome-scale analysis of protein functions and evolution. Nucleic Acids Res 2000, 28:33-36. 
30. Soltis PS, Soltis DE: The origin and diversification of angiosperms. Am J Bot 2004, 91:1614-1626.

31. Sabelli PA, Larkins BA: The development of endosperm in grasses. Plant Physiol 2009, 149:14-26

32. The Arabidopsis Genome Initiative: Analysis of the genome sequence of the flowering plant Arabidopsis thaliana. Nature 2000, 408:796-815.

33. Shoemaker RC, Schlueter J, Doyle JJ: Paleopolyploidy and genome duplication in soybean and other legumes. Curr Opin Plant Biol 2006, 9:104-109.

34. Schmutz J, Cannon SB, Schlueter J, Ma J, Mitros T, Nelson W, Hyten DL, Song Q, Thelen JJ, Cheng J, Xu D, Hellsten U, May GD, Yu Y, Sakurai T, Umezawa T, Bhattacharyya MK, Sandhu D, Valliyodan B, Lindquist E, Peto M, Grant D, Shu S, Goodstein D, Barry K, Futrell-Griggs M, Abernathy B, Du J, Tian Z, Zhu L, et al: Genome sequence of the palaeopolyploid soybean. Nature 2010, 463:178-183.

35. Swigonová Z, Lai J, Ma J, Ramakrishna W, Llaca V, Bennetzen JL, Messing J: Close split of sorghum and maize genome progenitors. Genome Res 2004, 14:1916-1923.

36. Tang $H$, Bowers JE, Wang $X$, Paterson AH: Angiosperm genome comparisons reveal early polyploidy in the monocot lineage. Proc Natl Acad Sci USA 2010, 107:472-477.

37. Youle RJ, Huang AH: Protein bodies from the endosperm of castor bean: Subfractionation, protein components, lectins, and changes during germination. Plant Physiol 1976, 58:703-709.

38. Hara I, Ohmiya M, Matsubara H: Pumpkin (Cucurbita sp) seed globulins III. Comparison of subunit structures among seed globulins of various Cucurbita species and characterization of peptide components. Plant Cell Physiol 1978, 19:237-243.

39. Hara-Nishimura I, Nishimura M, Matsubara H, Akazawa T: Suborganellar localization of proteinase catalyzing the limited hydrolysis of pumpkin globulin. Plant Physiol 1982, 70:699-703.

40. Utsumi S: Plant food protein engineering. In Advances in food and nutrition research. Volume 36. Edited by: Kinsella JE. San Diego: Academic Press; 1992:89-208.

41. Krishnan HB: Biochemistry and molecular biology of soybean seed storage proteins. J New Seeds 2000, 2:1-25.

42. Yamagata H, Sugimoto T, Tanaka K, Kasai Z: Biosynthesis of storage proteins in developing rice seeds. Plant Physiol 1982, 70:1094-1100

43. Furuta M, Yamagata H, Tanaka K, Kasai Z, Fuji S: Cell-free synthesis of the rice glutelin precursor. Plant Cell Physiol 1986, 27:1201-1204.

44. Laudencia-Chingcuanco DL, Vensel WH: Globulins are the main seed storage proteins in Brachypodium distachyon. Theor Appl Genet 2008, 117:555-563.

45. Krishnan HB, Natarajan SS, Mahmoud AA, Nelson RL: Identification of glycinin and $\beta$-conglycinin subunits that contribute to the increased protein content of high-protein soybean lines. J Agric Food Chem 2007, 55:1839-1845.

46. Narikawa T, Tamura T, Yagasaki K, Terauchi K, Sanmiya K, Ishimaru Y, Abe K, Asakura $T$ : Expression of the stress-related genes for glutathione $S$ transferase and ascorbate peroxidase in the most-glycinin-deficient soybean cultivar Tousan205 during seed maturation. Biosci Biotechnol Biochem 2010, 74:1976-1979.

47. Yagasaki K, Takagi T, Sakai M, Kitamura K: Biochemical characterization of soybean protein consisting of different subunits of glycinin. J Agric Food Chem 1997, 45:656-660.

48. Takahashi M, Uematsu Y, Kashiwaba K, Yagasaki K, Hajika M, Matsunaga R, Komatsu K, Ishimoto M: Accumulation of high levels of free amino acids in soybean seeds through integration of mutations conferring seed protein deficiency. Planta 2003, 217:577-586.

49. Guerche P, Tire C, De Sa FG, De Clercq A, Van Montagu M, Krebbers E: Differential expression of the Arabidopsis $2 S$ albumin genes and the effect of increasing gene family size. Plant Cell 1990, 2:469-478.

50. Jiao Y, Wickett NJ, Ayyampalayam S, Chanderbali AS, Landherr L, Ralph PE, Tomsho LP, Hu Y, Liang H, Soltis PS, Soltis DE, Clifton SW, Schlarbaum SE, Schuster SC, Ma H, Leebens-Mack J, dePamphilis CW: Ancestral polyploidy in seed plants and angiosperms. Nature 2011, 473:97-100.

51. Ridley M: Evolution Blackwell Science Ltd: Blackwell; 2004, 1-91, 3th version.

52. Löytynoja A, Goldman N: An algorithm for progressive multiple alignment of sequences with insertions. Proc Natl Acad Sci USA 2005, 102:10557-10562.
53. Tamura K, Peterson D, Peterson N, Stecher G, Nei M, Kumar S: MEGA5: molecular evolutionary genetics analysis using maximum likelihood, evolutionary distance, and maximum parsimony methods. Mol Biol Evol

54. Jones DT, Taylor WR, Thornton JM: The rapid generation of mutation data matrices from protein sequences. Comput Appl Bio Sci 1992, 8:275-282.

55. Ronquist F, Huelsenbeck JP: MrBayes 3: Bayesian phylogenetic inference under mixed models. Bioinformatics 2003, 19:1572-1574.

56. Yang Z: PAML 4: phylogenetic analysis by maximum likelihood. Mol BiOl Evol 2007, 24:1586-1591.

57. Ramsay H, Rieseberg LH, Ritland K: The correlation of evolutionary rate with pathway position in plant terpenoid biosynthesis. Mol Biol Evol 2009, 26:1045-1053.

58. Yang Z: Likelihood ratio tests for detecting positive selection and application to primate lysozyme evolution. Mol Biol Evol 1998, 15:568-573.

59. Yang Z, Nielsen R: Codon-substitution models for detecting molecular adaptation at individual sites along specific lineages. Mol Biol Evol 2002 19:908-917.

60. Zhang J, Nielsen R, Yang Z: Evaluation of an improved branch-site likelihood method for detecting positive selection at the molecular level. Mol Biol Evol 2005, 22:2472-2479.

61. Yang Z, Wong WSW, Nielsen R: Bayes empirical Bayes inference of amino acid sites under positive selection. Mol Biol Evol 2005, 22:1107-1118.

62. The Arabidopsis Genome Initiative: Analysis of the genome sequence of the flowering plant Arabidopsis thaliana. Nature 2000, 408:796-815.

63. Huang S, Li R, Zhang Z, Gu X, Fan W, Lucas W, Wang X, Xie B, Ni P, Ren Y, Zhu H, Li J, Lin K, Jin W, Fei Z, Li G, Staub J, Kilian A, van der Vossen EAG, Wu Y, Guo J, He J, Jia Z, Ren Y, Tian G, Lu Y, Ruan J, Qian W, Wang M, Huang $Q$, et al: The genome of the cucumber, Cucumis sativus L. Nat Genet 2009, 41:1275-1281.

64. Tuskan GA, Difazio S, Jansson S, Bohlmann J, Grigoriev I, Hellsten U, Putnam N, Ralph S, Rombauts S, Salamov, A Schein J, Sterck L, Aerts A, Bhalerao RR, Bhalerao RP, Blaudez D, Boerjan W, Brun A, Brunner A, Busov V, Campbell M, Carlson J, Chalot M, Chapman J, Chen GL, Cooper D, Coutinho PM, Couturier J, Covert S, Cronk Q, et al: The genome of black cottonwood, Populus trichocarpa (Torr. \& Gray). Science 2006, 313:1596-1604.

65. Chan AP, Crabtree J, Zhao Q, Lorenzi H, Orvis J, Puiu D, Melake-Berhan A, Jones KM, Redman J, Chen G, Cahoon EB, Gedil M, Stanke M, Haas BJ, Wortman JR, Fraser-Liggett CM, Ravel J, Rabinowicz PD, et al: Draft genome sequence of the oilseed species Ricinus communis. Nat Biotechnol 2010, 28:951-956.

66. The International Brachypodium Initiative: Genome sequencing and analysis of the model grass Brachypodium distachyon. Nature 2010, 463:763-768

67. Ouyang S, Zhu W, Hamilton J, Lin H, Campbell M, Childs K, Thibaud Nissen F, Malek RL, Lee Y, Zheng L, Orvis J, Haas B, Wortman J, Buell CR: The TIGR Rice Genome Annotation Resource: improvements and new features. Nucleic Acids Res 2007, , 35 Database: D883-887.

68. Schnable PS, Ware D, Fulton RS, Stein JC, Wei F, Pasternak S, Liang C, Zhang J, Fulton L, Graves TA, Minx P, Reily AD, Courtney L, Kruchowski SS, Tomlinson C, Strong C, Delehaunty K, Fronick C, Courtney B, Rock SM, Belter E, Du F, Kim K, Abbott RM, Cotton M, Levy A, Marchetto P, Ochoa K, Jackson SM, Gillam B, et al: The B73 maize genome: complexity, diversity, and dynamics. Science 2009, 326:1112-1115.

69. Paterson AH, Bowers JE, Bruggmann R, Dubchak I, Grimwood J, Gundlach H, Haberer G, Hellsten U, Mitros T, Poliakov A, Schmutz J, Spannagl M, Tang H, Wang X, Wicker T, Bharti AK, Chapman J, Feltus FA, Gowik U, Grigoriev IV, Lyons E, Maher CA, Martis M, Narechania A, Otillar RP, Penning BW, Salamov AA, Wang Y, Zhang L, Carpita NC, et al: The Sorghum bicolor genome and the diversification of grasses. Nature 2009, 457:551-556.

doi:10.1186/1471-2148-12-15

Cite this article as: Li et al:: Gene duplication and an accelerated evolutionary rate in $11 \mathrm{~S}$ globulin genes are associated with higher protein synthesis in dicots as compared to monocots. BMC Evolutionary Biology 2012 12:15. 